Article

\title{
Asymptomatic Strongyloidiasis among Latin American Migrants in Spain: A Community-Based Approach
}

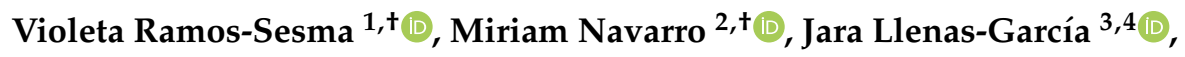 \\ Concepción Gil-Anguita ${ }^{5}$, Diego Torrús-Tendero ${ }^{6,7}{ }^{\circ}$, Philip Wikman-Jorgensen ${ }^{8}(\mathbb{1}$, \\ Concepción Amador-Prous ${ }^{5}$, María-Paz Ventero-Martín ${ }^{9}{ }^{\circledR}$, Ana-María Garijo-Sainz ${ }^{5}$, \\ María García-López ${ }^{3}$, Ana-Isabel Pujades-Tárraga ${ }^{5}$, Cristina Bernal-Alcaraz ${ }^{3}$, \\ Antonio Santonja ${ }^{5}$, Pedro Guevara-Hernández ${ }^{3}$, María Flores-Chávez ${ }^{10,11} \mathbb{D}$, \\ José-María Saugar ${ }^{11}$, José-Manuel Ramos-Rincón ${ }^{4,6, * \mathbb{D}}$ and Corazones Sin Chagas Platform $\ddagger$ \\ 1 Internal Medicine Service, HLA Inmaculada Hospital, 18004 Granada, Spain; violeta.ramos@grupohla.com \\ 2 Public Health, Science History and Gynecology Department, Universidad Miguel Hernández, \\ 03550 Sant Joan d'Alacant, Alicante, Spain; navarro_mirbel@gva.es \\ 3 Internal Medicine Service, Vega Baja Hospital-FISABIO, Orihuela, 03314 Alicante, Spain; \\ jllenas@umh.es (J.L.-G.); garcia_marialop@gva.es (M.G.-L.); \\ cristinabernalalcaraz@hotmail.com (C.B.-A.); pegueher@gmail.com (P.G.-H.) \\ 4 Clinica Medicine Department, University Miguel Hernández de Elche, 03550 Sant Joan d'Alacant, \\ Alicante, Spain \\ 5 Internal Medicine Service, Marina Baixa Hospital, La Vila Joiosa, 03570 Alicante, Spain; \\ gil_conang@gva.es (C.G.-A.); amador_con@gva.es (C.A.-P.); garijo_ana@gva.es (A.-M.G.-S.); \\ anabelpujades@gmail.com (A.-I.P.-T.); santonja_ant@gva.es (A.S.) \\ 6 Internal Medicine Service, General University Hospital of Alicante-ISABIAL, 03550 Alicante, Spain; \\ torrus_die@gva.es \\ 7 Department of Parasitology, Universidad Miguel Hernández de Elche, 03550 Alicante, Spain \\ 8 Internal Medicine Service, University Clinical Hospital Sant Joan d'Alacant-FISABIO, 03550 Alicante, Spain; \\ wikman_phi@gva.es \\ 9 Microbiology Service, General University Hospital of Alicante -ISABIAL, 03010 Alicante, Spain; \\ ventero_marmar@gva.es \\ 10 Foundation Mundo Sano, 28046 Madrid, Spain; maria.flores@mundo.sano.org \\ 11 Parasitology Service, National Center of Microbiology, 28222 Madrid, Spain; jmsaugar@isciii.es \\ * Correspondence: jose.ramosr@umh.es \\ + These authors contributed equally to this work. \\ $\ddagger$ Members of the Corazones Sin Chagas Platform: María García-López, Cristina Bernal-Alcaraz, Pedro B. \\ Guevara-Hernández, Jara Llenas-García, Joan Gregori-Colome, Ana Lucas-Dato, Esther Martínez-Birlanga \& \\ Estefanía García-Rodríguez (Hospital Vega Baja, Orihuela); José-Manuel Ramos Rincón, Diego \\ Torrús-Tendero, M ${ }^{a}$ Paz Ventero-Martín, Adelina Gimeno-Gascón, Ares Sánchez-Sánchez, Roser \\ Muñoz-Pérez, Carmen Almoedo Albero (Hospital General Universitario de Alicante), Concepción \\ Gil-Anguita, Concepción Amador-Prous, Concepción Amador Prous, Ana-Isabel Pujades-Tárraga, Antonio \\ Santonja, María Sánchez-Valera, \& Rosa Sánchez-García (Hospital Marina Baixa Villajoyosa), Miriam \\ Navarro Beltrá (Universidad Miguel Hernández), province of Alicante, Spain.
}

Received: 20 May 2020; Accepted: 20 June 2020; Published: 24 June 2020

Abstract: Strongyloides stercoralis infection is frequently underdiagnosed since many infections remain asymptomatic. Aim: To estimate the prevalence and characteristics of asymptomatic S. stercoralis infection in Latin American migrants attending a community-based screening program for Chagas disease in Spain. Methodology: Three community-based Chagas disease screening campaigns were performed in Alicante (Spain) in 2016, 2017, and 2018. Serological testing for S. stercoralis infection was performed using a non-automatized IVD-ELISA detecting IgG (DRG Instruments GmbH, Marburg, Germany). Results: Of the 616 migrants from Central and South America who were screened, 
601 were included in the study: 100 children and adolescents ( $<18$ years of age) and 501 adults. Among the younger group, 6 participants tested positive (prevalence $6 \%, 95 \%$ confidence interval [CI] $2.5 \%$ to $13.1 \%$ ), while 60 adults did so (prevalence $12 \%, 95 \%$ CI $9.3 \%$ to $15.3 \%$ ). S. stercoralis infection was more common in men than in women (odds ratio adjusted [ORa] 2.28, 95\% CI 1.289 to 4.03 ) and in those from Bolivia (ORa 2.03, 95\% CI 1.15 to 3.59). Prevalence increased with age (ORa 1.02, $95 \%$ CI 0.99 to 1.05). In contrast, a university education had a protective effect (ORa $0.29,95 \%$ CI 0.31 to 0.88$)$. Forty-one $(41 / 66 ; 62.1 \%)$ of the total cases of $S$. stercoralis infection were treated at the health care center. Positive stool samples were observed in $19.5 \%$ of the followed-up positive cases. Conclusion: Incorporating serological screening for S. stercoralis into community-based screening for Chagas disease is a useful intervention to detect asymptomatic S. stercoralis infection in Central and South American migrants and an opportunity to tackle neglected tropical diseases in a transversal way. The remaining challenge is to achieve patients' adherence to the medical follow-up.

Keywords: Strongyloidiasis; Strongyloides stercoralis; Chagas disease; Central and South America; Community-based intervention; migrants

\section{Introduction}

Strongyloidiasis, the human disease caused by infection with Strongyloides stercoralis [1], is a soil-transmitted helminthiasis with at least 30 to 100 million people infected globally [2]. The real prevalence is probably underestimated because of the low sensitivity of traditional diagnostic methods [3]. The medical importance of this infection resides in its capacity to remain clinically asymptomatic for years, persisting in the host for a lifetime as a result of autoinfection. Although it often causes nothing more than mild gastrointestinal, respiratory or cutaneous symptoms, alterations in the infected person's immune system can lead to hyperinfection syndrome, with dissemination of large numbers of larvae from gastrointestinal tracts and lungs to ectopic sites due to accelerated larval reproduction. This can result in severe systemic bacterial infections that may lead to multiorgan failure and death [4-6]. Hyperinfection and disseminated strongyloidiasis can be fatal, especially among immunocompromised individuals, with a reported mortality up to $62 \%$ [7-9].

The migrant population in Spain has increased significantly during the last fifteen years. In 2018, there were 6 million people from S. stercoralis-endemic countries living in Spain. This group includes 1.8 million people from South America and 500,000 from Central America and the Caribbean [10]. Latin America has been described as a region with high prevalence of chronic strongyloidiasis [11,12]. Many cases remain undetected for years in migrants' destination country because of their asymptomatic or mildly symptomatic nature $[6,13,14]$.

Diagnosing asymptomatic strongyloidiasis would enable its treatment, potentially preventing subsequent development of hyperinfection or disseminated strongyloidiasis [6,14]. Different authors in the United States and Europe have described experiences diagnosing asymptomatic Chagas disease in the community [15-18]. To our knowledge, however, there are no published strategies describing the diagnosis of asymptomatic strongyloidiasis through community-based interventions in high income-countries, apart from those in Madrid and Alicante (Spain) [19].

The burden and complexity of this silent and potentially lethal infection make it necessary to actively search for people with strongyloidiasis in order to offer them specific treatment and medical follow-up when indicated. The aim of this study is to describe the results of opportunistic serological screening for strongyloidiasis in Latin American migrants attending a community-based screening program for Chagas disease in Spain. 


\section{Material and Methods}

\subsection{Study Population}

This was a cross-sectional study conducted during three community screening campaigns for Chagas disease and strongyloidiasis, involving three centers in the province of Alicante (Spain) and taking place on 31 January 2016, 30 May 2017, and 28 October 2018. Alicante is a Spanish province located in south-eastern Spain. It has a population of 1.8 million people, of whom about $13.8 \%$ are migrants. Around 48,700 of these come from Central and South America [20]. Callosa d'en Sarrià is a city located about $40 \mathrm{~km}$ north of Alicante city, and Orihuela is $60 \mathrm{~km}$ to the south (Figure 1).
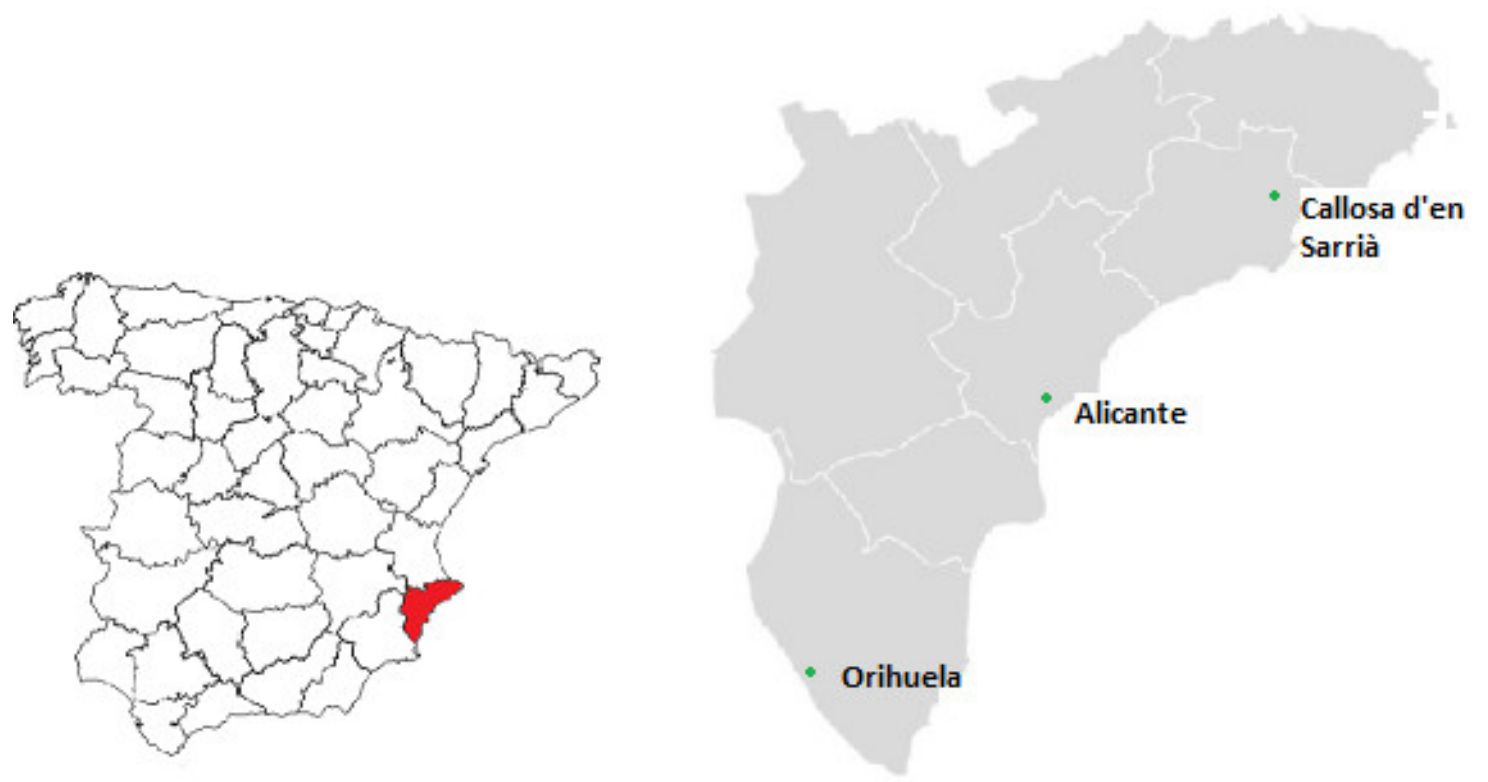

Figure 1. Map of Spain, with Alicante city, Callosa d'en Sarrià and Orihuela.

The 2016 and 2017 campaigns were organized by a multidisciplinary team belonging to ISABIAL/FISABIO Research Foundation, the General University Hospital of Alicante, and the Foundation Mundo Sano, and they were performed in the abovementioned hospital. The 2018 campaign was organized by a multidisciplinary team belonging to the ISABIAL/FISABIO Research Foundation and three hospitals in Alicante province, (Alicante city, Villajoyosa and Orihuela) and was performed simultaneously in the General University Hospital of Alicante and two primary healthcare centers (Callosa d'en Sarrià and Álvarez de la Riva in Orihuela).

The inclusion criteria were: all adult participants who attended the community screening campaigns for Chagas disease and strongyloidiasis signed the informed consent, and for non-adult participants their parents or tutors gave their written consent. We excluded adults born in Spain, participants who did not undergo serological testing, and participants in whom the serum specimen was insufficient.

Trained Latin American community health workers promoted the event for a few weeks before the date of its celebration. Latin American migrants were informed through the dissemination of informative leaflets and posters at key locations (NGOs, small businesses, restaurants, shops, markets, etc.); informative talks at local Latin American meeting points and community events (e.g., sporting events); and social networks and media aimed at the Latin American population (radio and newspapers).

\subsection{Questionnaires}

Before the blood extraction, all participants completed a questionnaire eliciting epidemiological data. An additional questionnaire, used primarily to assess the level of knowledge about Chagas 
disease, also contained a question about strongyloidiasis: "Have you ever heard of the Strongyloides parasite or strongyloidiasis?" Medical doctors and medical or nursing students were always available for assistance.

\subsection{Procedure: Serological Methods}

Detection of Strongyloides IgG antibodies was performed using the Strongyloides IgG IVD-ELISA kit (DRG Instruments GmbH, Marburg, Germany). It includes microtiter wells coated with a soluble fraction of S. stercoralis L3 filariform larval antigen. The test was considered positive if the index (optical density [OD] measure of the sample divided by the cutoff value) was more than 1.1. The result was considered borderline if the index was between 1.0 and 1.1. Analyses were performed in the Parasitology Department of the National Center for Microbiology-Health Institute Carlos III (DP-NCM-ISCIII) in Madrid.

\subsection{Follow-Up of Participants with Positive Serology}

Participants with positive serology for strongyloidiasis were traced and offered specialized outpatient clinical management by a medical doctor at their refence hospital.

Their full medical history was taken, and other tests were done to complete the study according to their physician's criteria. Tests included one or several samples to examine S. stercoralis in feces (Baermann technique, agar plate culture, or a molecular diagnostic method (real-time polymerase chain reaction [RT-PCR]), depending of the protocol in each hospital, and a complete blood test with eosinophil count and IgE levels [21-23]. The Strongyloides RT-PCR was performed in the DP-NCM-ISCIII, following the same methodology described by Saugar et al. 2015 [23].

The cases were treated with one or two doses of ivermectin $(200 \mu \mathrm{g} / \mathrm{kg} /$ day $)$ [24]. Because treatment protocols are not standardized in the study centers, some patients were treated on day 1 and 14 , while others took the drug on two consecutive days.

Cure was defined as: (1) negative stool examination and decrease of initial eosinophil count by at least half, and/or (2) seroconversion or at least half of initial OD/relative light units values for ELISA tests, six months after treatment completion [25].

\subsection{Statistical Analysis}

Categorical data are presented as absolute and relative frequencies, and continuous variables as medians and interquartile ranges (IQRs). Lower and upper limits of the $95 \%$ confidence interval (CI) for prevalence were calculated following the methods described by Newcombe et al. The chi-square test or Fisher's exact tests were used, as appropriate, to compare the distribution of categorical variables, and the Mann-Whitney $U$ test was used for continuous variables. Associations were measured using the odds ratio (OR) with a 95\% CI. Following univariable analyses, we fit a multivariable multiple regression model using a forward stepwise approach to identify variables independently associated with a specific infection. Results were considered statistically significant if the two-tailed $p$ value was less than 0.05. SPSS Statistics for Windows, Version 21.0 (IBM Corp., Armonk, NY, USA) was used for statistical analysis. 


\subsection{Ethical Considerations}

The STROBE statement guidelines were followed in the conducting and reporting of the study (Table S1). Procedures were performed in accordance with the ethical standards set out in the Declaration of Helsinki, as revised in 2013. All three community-based screening campaigns were approved by the General University Hospital of Alicante Ethics Committee (Valencian Healthcare Agency; ref: CEIC PI2015/16 and ref. CEI PI2018/035). All participants signed written informed consent.

\section{Results}

Of the 616 people who took part in the screening, 601 were included in the study. Figure 2 shows the participant flow chart.

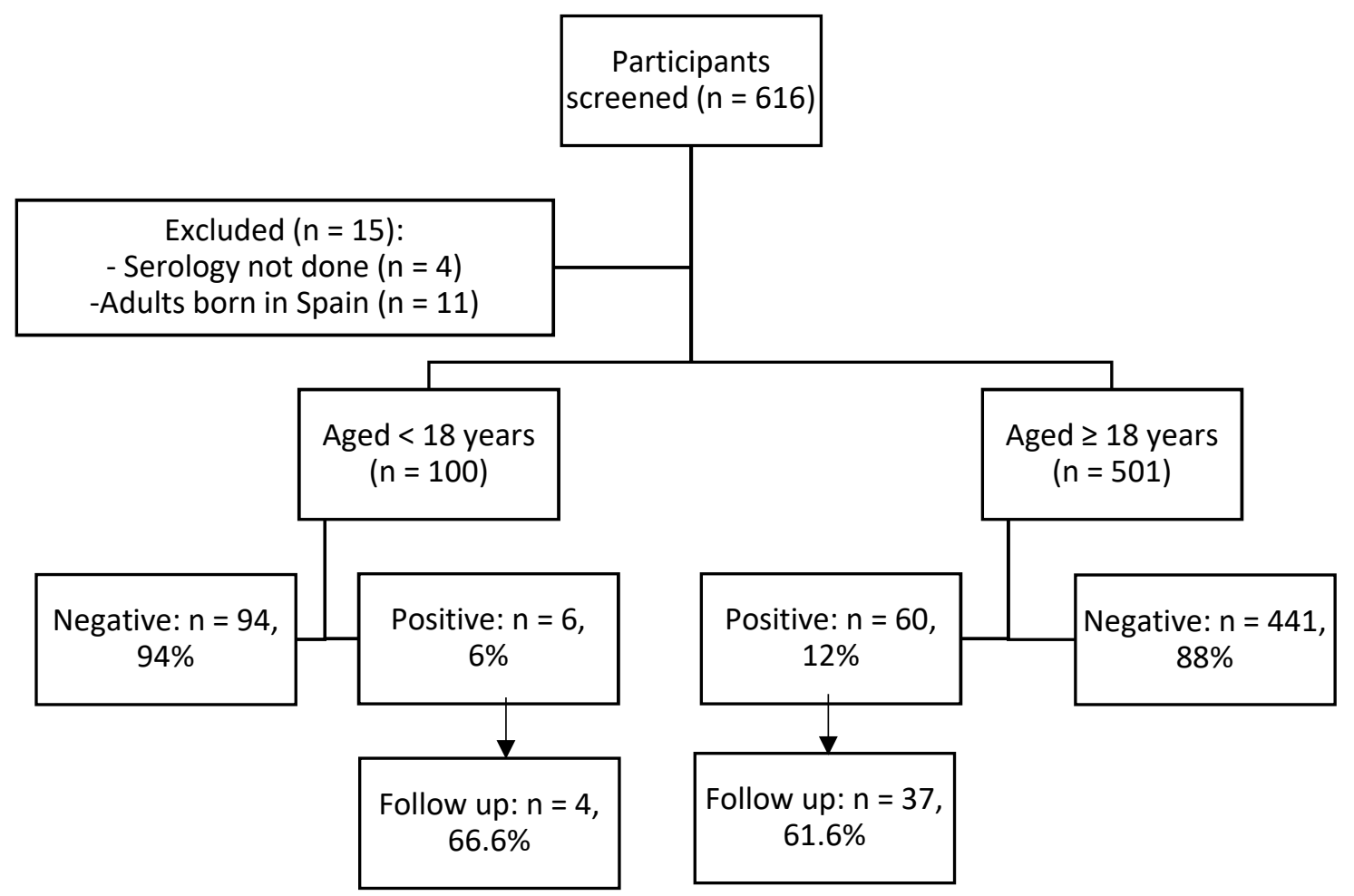

Figure 2. Participants flow chart.

Of the 601 participants, 128 were screened in 2016, 114 in 2017, and 359 in 2018. There were $100(16.6 \%)$ children and adolescents ( $<18$ years) and $501(83.9 \%)$ adults ( $\geq 18$ years). 


\subsection{S. stercoralis Infection in Children and Adolescents}

The population screened aged under 18 years included 57 girls $(57 \%)$, and the sample had a median age of 11 years; $74 \%$ were born in Spain (Table 1). Six tested positive for S. stercoralis infection (prevalence $6 \%, 95 \%$ CI $2.5 \%$ to $13.1 \%$ ). The median values of ELISA titers was 1.3 (IQR 1.7 to 3.5; range 1.2 to 7.8), and these participants were younger than those who were not infected (median 5 vs 12 years old, OR $0.58,95 \%$ CI 0.39 to 0.85 ). All six infected children were born in Spain, but their mothers were from Ecuador $(n=3)$, Bolivia $(n=2)$, and Colombia $(n=1)$. All had traveled to their parents' country of origin in the last three years.

Table 1. Characteristics of children and adolescent participants with and without $S$. stercoralis infection.

\begin{tabular}{cccccc}
\hline & $\begin{array}{c}\text { Total } \\
(\mathbf{n}=\mathbf{1 0 0})\end{array}$ & $\begin{array}{c}\text { S. stercoralis } \\
\text { Infection } \\
(\mathbf{n}=\mathbf{6})\end{array}$ & $\begin{array}{c}\text { No Infection } \\
\mathbf{( n = 9 4 )}\end{array}$ & OR (95\% CI) & $p$ Value \\
\hline $\begin{array}{c}\text { Demographics } \\
\text { Boys, } \mathrm{n}(\%)\end{array}$ & $43(43)$ & $4(66.7)$ & $2(2.1)$ & $2.82(0.49-16.17)$ & 0.23 \\
$\begin{array}{c}\text { Median age, years (IQR) }(\mathrm{n}=69) \\
\text { Country of birth, } \mathrm{n}(\%)\end{array}$ & $11(9-14)$ & $5(4-6)$ & $12(10-14)$ & $0.58(0.39-0.85)$ & 0.001 \\
Spain * & $74(74)$ & $6(100)$ & $68(72.3)$ & NA & 0.13 \\
Bolivia & $13(13)$ & 0 & $13(13.8)$ & NA & 0.99 \\
Ecuador & $9(9)$ & 0 & $9(9.6)$ & NA & 0.99 \\
Argentina & $2(0)$ & 0 & $2(0.1)$ & NA & 0.99 \\
Uruguay & $2(2)$ & $0(0.0)$ & $2(0.1)$ & NA & 0.99 \\
\hline
\end{tabular}

IQR: interquartile range, OR: odds ratio; CI: confidence intervals, ${ }^{*}$ Children born in Spain, whose mother comes from Latin America. Nationality of the mother: (positive/negative): Bolivia $(n=2 / 35)$, Ecuador $(n=3 / 28)$, Colombia $(\mathrm{n}=1 / 6)$, Argentina $(0 / 1)$, not available $(\mathrm{n}=0 / 4)$.

\subsection{S. stercoralis Infection in Adult Participants}

Of the 501 adult participants, most were women $(n=303,60.5 \%)$, and the median age was 41 years. The main countries of birth were Bolivia (40.3\%) and Ecuador (37.5\%), and they had been in Spain for a median time of 11 years. Only $7.9 \%$ had heard of Strongyloides parasites (Table 2). In total, 60 were positive for $S$. stercoralis infection (prevalence $12 \%, 95 \%$ CI $9.3 \%$ to $15.3 \%$ ). The median value ELISA titers was 4.8, (IQR 1.9 to 10.5 ; range 1.1 to 22.3 ).

Table 2 shows the epidemiological characteristics of participants with and without $S$. stercoralis infection. Strongyloidiasis was more common in men and in those born in Bolivia but less common in those who had completed university studies. Prevalence increased slightly with age. In the multivariable analysis S. stercoralis infection was associated with male sex (adjusted OR $2.28,95 \%$ CI 1.9 to 4.03 ) and birthplace in Bolivia (OR 2.03, 95\% CI 1.15 to 3.58). Completion of university studies was a protective factor (adjusted OR $0.29,95 \%$ CI 0.10 to 0.88 ).

Of the 60 participants with S. stercoralis infection, 14 (23.3\%; $95 \%$ CI $13.8 \%$ to $36.2 \%)$ had positive Trypanosoma cruzi serology. All were from Bolivia. The prevalence of strongyloidiasis-Chagas co-infections in Bolivians was $11.4 \%$ (95\% CI 7.5\% to 16.8\%). 
Table 2. Characteristics of adult participants with and without S. stercoralis infection.

\begin{tabular}{|c|c|c|c|c|c|c|c|}
\hline & $\begin{array}{c}\text { Total } \\
(n=501)\end{array}$ & $\begin{array}{l}\text { S. stercoralis } \\
\text { Infection } \\
(\mathrm{n}=60)\end{array}$ & $\begin{array}{l}\text { No Infection } \\
\quad(\mathrm{n}=441)\end{array}$ & OR $(95 \%$ CI $)$ & $p$ Value & ORa $(95 \%$ CI) & $p$ Value \\
\hline \multicolumn{8}{|l|}{ Demographics } \\
\hline Men, n (\%) & $198(39.5)$ & $34(56.7)$ & $164(37.2)$ & $2.20(1.28-3.81)$ & 0.004 & $2.28(1.29-4.03)$ & 0.004 \\
\hline Median age, years (IQR) $(n=493)$ & $41(34-49)$ & $44(37-51)$ & $41(34-49)$ & $1.02(1.00-1.04)$ & 0.046 & $1.02(0.99-1.05)$ & 0.064 \\
\hline \multicolumn{8}{|c|}{ Education, $\mathrm{n}(\%)(\mathrm{n}=478)$} \\
\hline Primary school & $128(26.9)$ & $21(35.6)$ & $107(25.5)$ & $1.61(0.90-2.86)$ & 0.10 & - & \\
\hline Secondary school & $226(55.6)$ & $34(57.6)$ & $232(55.4)$ & $1.09(0.63-1.90)$ & 0.71 & - & \\
\hline University studies & $84(17.6)$ & $4(6.8)$ & $80(19.1)$ & $0.30(0.10-0.87)$ & 0.02 & $0.29(0.31-0.88)$ & 0.029 \\
\hline \multicolumn{8}{|c|}{ Country of birth, $\mathrm{n}(\%)$} \\
\hline Bolivia & $202(40.3)$ & $33(55)$ & $169(38.3)$ & $1.96(1.14-3.38)$ & 0.013 & $2.03(1.15-3.59)$ & 0.014 \\
\hline Ecuador & $188(37.5)$ & $19(31.7)$ & $169(38.3)$ & $0.74(0.41-1.32)$ & 0.32 & - & \\
\hline Colombia & $65(13.0)$ & $6(10.0)$ & $59(13.4)$ & $0.71(0.29-1.74)$ & 0.46 & - & \\
\hline Argentina & $13(2.6)$ & $1(1.7)$ & $12(2.7)$ & $0.60(0.07-4.75)$ & 0.63 & - & \\
\hline Brazil & $7(1.4)$ & $0(0.0)$ & $7(1.6)$ & NA & 0.99 & - & \\
\hline Paraguay & $6(1.2)$ & $0(0.0)$ & $6(1.4)$ & NA & 0.99 & - & \\
\hline Dominican Republic & $4(0.8)$ & $0(0.0)$ & $4(0.9)$ & NA & 0.99 & - & \\
\hline Peru & $4(0.8)$ & $0(0.0)$ & $4(0.9)$ & NA & 0.99 & - & \\
\hline Venezuela & $4(0.8)$ & $0(0.0)$ & $4(0.9)$ & NA & 0.99 & - & \\
\hline Other * & $8(1.6)$ & $1(1.7)$ & $7(1.6)$ & $1.01(0.12-8.69)$ & 0.99 & - & \\
\hline
\end{tabular}

Knowledge about disease, $\mathrm{n}$ affirmative response $(\%)$

Have you ever heard of

Strongyloides parasite or

$39(7.9)$

$1(1.7)$

$38(8.7)$

$0.18(0.02-1.35)$

0.07

IQR: interquartile range, OR: odds ratio; ORa: adjusted odds ratio; CI: confidence intervals, ${ }^{*}$ Other countries: Nicaragua $(n=2)$, Uruguay $(n=2)$, Honduras $(n=2)$, Mexico $(n=2)$. 


\subsection{Follow-Up of Participants with S. stercoralis Positive Serology}

Twenty-five of the 66 (37.5\%) total positive participants were lost to follow-up (Table 3). Of the 41 infected patients who did present to the outpatient clinic at least once, a fecal parasitological analysis was done in 35; 8 (19.5\%) samples were positive for S. stercoralis larvae. Eosinophilia was detected in 16/27 (59.2\%) patients, and IgE values were indicative of infection in 9/10 (90\%). Treatment was offered to 28 patients; the rest did not come back to the following appointments or were checked once as outpatients. Twenty-eight patients were treated, of whom 12 were confirmed as cured. Four were lost to follow-up and 12 were still under follow-up at the time of writing.

Table 3. Follow-up after screening campaign in children and adults with S. stercoralis positive serology.

\begin{tabular}{|c|c|c|c|}
\hline Variable & $\begin{array}{c}\text { Total } \\
\text { n/N (\%) }\end{array}$ & $\begin{array}{l}\text { Children } \\
\text { n/N (\%) }\end{array}$ & $\begin{array}{l}\text { Adults } \\
\text { n/N (\%) }\end{array}$ \\
\hline S. stercoralis infection & 66/601 (11) & $6 / 100(6)$ & $60 / 501(11)$ \\
\hline \multicolumn{4}{|l|}{ Follow-up of patients } \\
\hline Available & $41 / 66(62.1)$ & $4 / 6(66.6)$ & $37 / 60(61.6)$ \\
\hline Unavailable & $25 / 66(37.9)$ & $2 / 6(33.3)$ & $23 / 60(38.3)$ \\
\hline \multicolumn{4}{|l|}{ Reason for not following up } \\
\hline No phone contact & $17 / 25(68)$ & $1 / 2(50)$ & $16 / 23(69.5)$ \\
\hline Current phone not available & $7 / 25(28)$ & $1 / 2(50)$ & $6 / 23(26.1)$ \\
\hline Picked up the phone, but did not go to the appointment & $1 / 25(4)$ & 0 & $1 / 23(4.3)$ \\
\hline \multicolumn{4}{|l|}{ Follow-up for confirmation } \\
\hline \multicolumn{4}{|l|}{ Stool examination } \\
\hline Negative & $27 / 41(65.9)$ & $2 / 4(50)$ & $23 / 37(62.2)$ \\
\hline Positive * & $8 / 41(19.5)$ & 0 & $8 / 37(21.6)$ \\
\hline Not recovered & 6/41 (14.6) & & \\
\hline Eosinophilia (>5\% leukocyte or $>500$ eosinophils) & $16 / 27(59.2)$ & $1 / 1(100)$ & $15 / 26(57.7)$ \\
\hline $\operatorname{IgE}>100$ & $9 / 10(90)$ & $1 / 1(100)$ & $8 / 9(88.8)$ \\
\hline \multicolumn{4}{|l|}{ Outcome } \\
\hline Treatment & $28 / 41(68.3)$ & $2 / 4(50)$ & $26 / 37(70.2)$ \\
\hline \multicolumn{4}{|l|}{ Results of treatment ${ }^{\dagger}$} \\
\hline Cure & $12 / 28(42.9)$ & 0 & $12 / 26(46.2)$ \\
\hline Ongoing & $12 / 28(42.9)$ & 0 & $10 / 26(38.4)$ \\
\hline Lost to follow-up after treatment & $4 / 28(14.2)$ & $2 / 4(50)$ & $4 / 26(15.4)$ \\
\hline
\end{tabular}

${ }^{*}$ Real-time polymerase chain reaction (RT-PCR) in stool $(\mathrm{n}=13)$, stool culture $(\mathrm{n}=27)$, both RT-PCR and culture $(\mathrm{n}=13) .{ }^{\dagger}$ All patients that finished treatment $(12 / 12)$ were cured.

\section{Discussion}

Global migration from S. stercoralis-endemic regions has increased the potential individual and public health impact of this parasitic NTD [26]. Active searches for susceptible people have proven effective in increasing its diagnosis $[13,27,28]$, enabling prompt treatment and prevention of further transmission and hyperinfection syndrome [26,27].

S. stercoralis infection is estimated to have a prevalence of between $7 \%$ and $40 \%$ among migrants, depending on the survey and patients' country of origin [14,29]. In a recent meta-analysis of the prevalence of strongyloidiasis in migrants from endemic areas who reside in Spain, the authors found an overall prevalence of $14 \%$ in Latin Americans [30]. Our study showed a lower prevalence than that ( $6 \%$ in children and adolescents and $12 \%$ in adults; $11 \%$ overall), but a similar proportion as another study performed in Spain, where the prevalence was 10.9\% in patients from South America [3].

We found significant differences in strongyloidiasis prevalence by sex, an observation that does not match the results of other articles [29]. On the other hand, we also found a significant difference in relation with age, which is consistent with other studies performed in endemic areas [9,31]. 
The prevalence of co-infection between T. cruzi and S. stercoralis is not negligible [29,32]. In our study, 14 of 60 adults (23.3\%, or around one in five cases) with S. stercoralis infection had also positive T. cruzi serology. Our results are similar to those reported by a Spanish Collaborative Network, where the co-infection prevalence was 21\% [26]. Moreover, Salvador et al. [33] have found that patients with Chagas disease and positive $S$. stercoralis serology had a higher proportion of DNA of T. cruzi by RT-PCR in peripheral blood than those with negative Strongyloides serology, which reflects the potential immunomodulatory effects of $S$. stercoralis in T. cruzi co-infected patients. Both of the infections are neglected diseases, so co-infection is normally underestimated in published studies [32-34].

Regarding strongyloidiasis in children, S. stercoralis was detected in $6 \%$ of the participants aged under 18 years. In endemic countries with poor sanitation or inadequate water supply, S. stercoralis infection is common in this age group [1,2] and causes nutritional impairment, with the important consequences that this implies in children [35]. However, few studies have specifically analyzed the relevance of serology for the diagnosis of chronic $S$. stercoralis infections in children in non-endemic countries [36]. In our study, most of the children screened were born in Spain, but at least one of their parents came from Latin America. All six children with positive S. stercoralis serology had traveled to their parents' countries in the recent past, so they should be considered migrants visiting friends and relatives. This community-based approach poses an opportunity to perform health education about the global health risks and preventative measures before, during, and after travelling [37], and it may lead to a reduction in the number of future disseminated strongyloidiasis cases. The low titers shown on the ELISA may be due to cross-reactivity.

Regarding knowledge of strongyloidiasis in the community, only $8 \%$ of the adult respondents had heard of the parasite. This result is not surprising, as human strongyloidiasis has been repeatedly pointed out as a largely neglected entity [4], and one characteristic of NTDs is the low awareness of them. This lack of awareness is not limited to the populations at risk but also extends to future healthcare professionals [38].

The determination of IgG by ELISA is a good technique for the screening of chronic S. stercoralisinfected patients $[29,36]$. The confirmatory diagnosis of $S$. stercoralis infection is based on the detection of larvae in stool samples, but in most chronic asymptomatic patients, the intestinal worm load is very low, and the output of larvae is minimal and irregular [36,39]. In our study, $19 \%$ of the screen-positive samples showed confirmation of larvae in stool culture (stool direct observation) or by detection of parasite DNA. This result is concordant with results obtained in other studies performed among migrants living in Europe, where less than $20 \%$ of the patients with positive serology have positive results by stool microscopy $[36,39]$. There are differences in the sensitivity of these methods i.e., examining S. stercoralis in feces by parasitological methods (Baermann technique or agar plate culture) and a molecular diagnostic method. The sensitivity of RT-PCR is higher than parasitological methods only, including serology [40].

We had a high rate of attrition in screened positive patients. Only two-thirds attended the first clinical visit, and less than half returned to receive strongyloidiasis treatment. The rate of loss to follow-up increases with the interval between the screening and the medical appointment. Lack of presentation to the consultation also increases with subsequent follow-up visits. This conclusion is similar to that of other studies on Chagas disease, where only about half of patients diagnosed after an additional test presented for treatment [41,42]. The reasons are diverse: difficulties with contacting patients, structural barriers, high mobility of the migrant population in and outside of the country, and the asymptomatic nature of $S$. stercoralis infection, among others [43]. Strategies to optimize retention must be an essential component of future interventions and could include administering treatment at the first visit, making sure sufficient contact information is provided, using telemedicine to minimize visits to the hospital, tracing patients with high mobility, and improving communication between primary and hospital healthcare and between hospitals of different geographical settings. Nevertheless, some barriers will be quite difficult to overcome, such as the structural ones, especially regarding the host country [44] 
About half of our participants treated for S. stercoralis infection were lost to follow-up or had not yet completed the six-month follow-up period at the time of writing. This result is comparable to other studies [39]. Most cases that had completed follow-up by the end of the study had been cured of chronic S. stercoralis infection. In that regard, S. stercoralis serology is useful for post-treatment follow-up, as also observed by several research studies in immigrant populations in Europe and North America $[39,44]$.

Given the low adherence to treatment and follow-up of our participants, offering S. stercoralis treatment and follow-up at a primary healthcare level is warranted. A recent review about different strategies for S. stercoralis screening and treatment among migrants is pointing in that direction [43].

This study has several limitations. First, it was a cross-sectional study conducted in Alicante, so the findings might not be generalizable to populations that are very different from our sample. Second, most of the participants were from Bolivia, because at its inception, our community-based campaign was designed to diagnose Chagas disease; diagnosis of $S$. stercoralis was an added value for its participants. Thus, the main target population was Bolivian migrants, who make up more than $80 \%$ of the Chagas patients in Spain [45]. There is less representation from other countries of origin like Colombia, Argentina, or Paraguay, and none from the Caribbean. Third, there were some difficulties in contacting patients, making appointments, and ensuring their presentation to the clinic. Furthermore, the questionnaire could have been more specific, asking more details about recent travel, including the length and specific places that were visited, in order to collect precise epidemiological data and draw more robust conclusions among the participants who had visited their home country to visit relatives and friends. Finally, there was no uniform protocol for action in the different healthcare centers where treatment and medical follow-up took place.

\section{Conclusions}

In our study we found an $11 \%$ prevalence of strongyloidiasis among the migrants, which is similar to other studies performed in Spain, despite our limitations and the regional nature of our campaign. Community-based interventions such as the screening campaigns described in this manuscript, which actively search for patients with chronic $S$. stercoralis infection, are scarce. The strategy of linking S. stercoralis screening with community-based screening for Chagas disease is a useful, convenient, and efficient intervention to detect asymptomatic strongyloidiasis in Latin American migrants. Moreover, it represents an opportunity to tackle NTDs in a transversal way.

The European Centre for Disease Prevention and Control recommends screening newly arrived migrants for strongyloidiasis [46,47], particularly immunosuppressed individuals [48], given the potential individual morbidity and mortality. However, this is not widely performed. It is important to also address the barriers to proper follow-up of positive cases in future campaigns, as only two-thirds of infected participants finally received care for the disease. Larger and more in-depth studies are needed to confirm the benefits of community-based screening for chronic $S$. stercoralis infection and the economic impact of preventing a severe symptomatic infection.

Supplementary Materials: The following are available online at http://www.mdpi.com/2076-0817/9/6/511/s1, Table S1: STROBE statement-Checklist of items that should be included in reports of cross-sectional studies.

Author Contributions: V.R.-S.: formal analysis, investigation, software, supervision, writing-original draft, writing-review and editing. M.N.: conceptualization, formal analysis, methodology, project administration, supervision, writing-original draft, writing - review and editing, designed the study, analyzed clinical data; J.L.-G.: conceptualization, methodology, supervision, writing-original draft, writing — review and editing; C.G.-A.: methodology, writing-review and editing draft; D.T.-T.: methodology, supervision, writing-original draft, writing-review and editing; P.W.-J.: methodology, writing-original draft, writing-review and editing; C.A.-P.: methodology, supervision, writing-review and editing draft; M.-P.V.-M.: methodology, writing-review and editing draft; A.-M.G.-S.: methodology, writing-review and editing draft; M.G.-L.: methodology, writing-review and editing draft; A.-I.P.-T.: methodology, writing-review and editing draft; C.B.-A.: methodology, writing-review and editing draft; A.S.: methodology, writing-review and editing draft; P.G.-H.: methodology, writing — review and editing draft; M.F.-C.: methodology, writing-review and editing draft; J.-M.S.: methodology, writing—review and editing draft; J.-M.R.-R.: conceptualization, formal analysis, 
methodology, project administration, supervision, writing — original draft, writing—review and editing designed the study, analyzed clinical data, and prepared, and reviewed the manuscript. All authors have read and agreed to the published version of the manuscript.

Funding: This study was partially supported by the 3rd call for research project grants for the Institute of Health and Biometric Research of Alicante (ISABIAL)/FISABIO Foundation (UGP-16-158), and by the collaboration agreement regulated under the Law of Patronage between ISABIAL/FISABIO and the Foundation Mundo Sano, Spain.

Acknowledgments: We extend thanks to all members of the Corazones Sin Chagas Platform for their active contribution to the program for the last 3 years, and to Salud Entre Culturas (www.saludentreculturas.es) for their collaboration in all our campaigns. We also thank Marcela González for coordinating the media campaigns, and Meggan Harris for her assistance in editing.

Conflicts of Interest: The authors declare no conflict of interest.

\section{References}

1. Krolewiecki, A.; Nutman, T.B. Strongyloidiasis: A Neglected Tropical Disease. Infect. Dis. Clin. N. Am. 2019, 33, 135-151. [CrossRef] [PubMed]

2. Schär, F.; Trostdorf, U.; Giardina, F.; Khieu, V.; Muth, S.; Marti, H.; Vounatsou, O.; Odermatt, P. Strongyloides stercoralis: Global Distribution and Risk Factors. PLoS Negl. Trop. Dis. 2013, 7, e2288. [CrossRef] [PubMed]

3. Requena-Méndez, A.; Salas-Coronas, J.; Salvador, F.; Gomez-Junyent, J.; Villar-Garcia, J.; Santin, M.; Muñoz, C.; González-Cordón, A.; Cabézas-Fernández, M.T.; Sulleiro, E.; et al. High Prevalence of Strongyloidiasis in Spain: A Hospital-Based Study. Pathogens 2020, 9, 107. [CrossRef] [PubMed]

4. Keiser, P.B.; Nutman, T.B. Strongyloides stercoralis in the Immunocompromised Population. Clin. Microbiol. Rev. 2004, 17, 208-217. [CrossRef]

5. Stewart, D.M.; Ramanathan, R.; Mahanty, S.; Fedorko, D.P.; Janik, J.E.; Morris, J.C. Disseminated Strongyloides stercoralis infection in HTLV-1-associated adult T-cell leukemia/lymphoma. Acta Haematol. 2011, 126, $63-67$. [CrossRef] [PubMed]

6. Buonfrate, D.; Formenti, F.; Perandin, F.; Bisoffi, Z. Novel approaches to the diagnosis of Strongyloides stercoralis infection. Clin. Microbiol. Infect. 2015, 21, 543-552. [CrossRef] [PubMed]

7. Belhassen-García, M.; Alonso-Sardón, M.; Martinez-Perez, A.; Soler, C.; Carranza-Rodriguez, C.; Pérez-Arellano, J.L.; Soil-Trasmitted Helminths Study group of the SEMTSI. Surveillance of strongyloidiasis in Spanish inpatients (1998-2014). PLoS ONE 2017, e0189449. [CrossRef]

8. Martinez-Perez, A.; Roure Díez, S.; Belhassen-Garcia, M.; Torrús-Tendero, D.; Perez-Arellano, J.L.; Cabezas, T.; Soler, C.; Díaz-Menéndez, M.; Navarro, M.; Trebiño, B.; et al. Management of severe strongyloidiasis attended at reference centers in Spain. PLoS Negl. Trop. Dis. 2018, 12. [CrossRef]

9. Guevara, A.G.; Anselmi, M.; Bisoffi, Z.; Prandi, R.; Márquez, M.; Silva, R.; Vicuña, Y.; Calvaopiña, M.; Cevallos, W.; Pérez, J.; et al. Mapping the Prevalence of Strongyloides stercoralis Infection in Ecuador: A Serosurvey. Am. J. Trop. Med. Hyg. 2019. [CrossRef]

10. Indice Nacional de Estadistica. España en cifras [Internet]. INE, Ed.; 2018. Available online: http: //www.ine.es/prodyser/espa_cifras (accessed on 2 November 2019).

11. Buonfrate, D.; Mena, M.A.; Angheben, A.; Requena-Mendez, A.; Munõz, J.; Gobbi, F.; Albonico, M.; Gotuzzo, E.; Bisoffi, Z.; COHEMI Project Study Group. Prevalence of strongyloidiasis in Latin America: A systematic review of the literature. Epidemiol. Infect. 2015, 143, 452-460. [CrossRef]

12. Morales, M.L.; Lopez, M.; Ly, P.; Anjum, S.; Fernandez-Baca, M.V.; Valdivia-Rodriguez, A.M.; Mamani-Licona, F.M.; Baca-Turpo, B.B.; Farfan-Gonzáles, N.; Chaman-Illanes, Y.; et al. Strongyloides stercoralis Infection at Different Altitudes of the Cusco Region in Peru. Am. J. Trop. Med. Hyg. 2019, 101, 422-427. [CrossRef] [PubMed]

13. Ramos, J.M.; Leon, R.; Andreu, M.; de las Parras, E.R.; Rodriguez-Diaz, J.C.; Esteban, A.; Esteban, A.; Saugar, J.M.; Torrús, D. Serological study of Trypanosoma cruzi, Strongyloides stercoralis, HIV, human T cell lymphotropic virus (HTLV) and syphilis infections in asymptomatic Latin-American immigrants in Spain. Trans. R. Soc. Trop. Med. Hyg. 2015, 109, 447-453. [CrossRef] [PubMed]

14. Asundi, A.; Beliavsky, A.; Liu, X.J.; Akaberi, A.; Schwarzer, G.; Bisoffi, Z.; Requena-Méndez, A.; Shrier, I.; Greenaway, C. Prevalence of strongyloidiasis and schistosomiasis among migrants: A systematic review and meta-analysis. Lancent Glob Health 2019, 7, e236-e248. [CrossRef] 
15. Navarro, M.; Berens-Riha, N.; Hohnerlein, S.; Seiringer, P.; Von Saldern, C.; Garcia, S.; Blasco-Hernández, T.; Navaza, B.; Shock, J.; Bretzel, G.; et al. Cross-sectional, descriptive study of Chagas disease among citizens of Bolivian origin living in Munich, Germany. BMJ Open 2017, 7, e013960. [CrossRef]

16. Romay-Barja, M.; Boquete, T.; Martinez, O.; González, M.; Álvarez-Del Arco, D.; Benito, A.; Blasco-Hernández, T. Chagas screening and treatment among Bolivians living in Madrid, Spain: The need for an official protocol. PLoS ONE 2019, 14, e0213577. [CrossRef] [PubMed]

17. Gómez I Prat, J.; Peremiquel-Trillas, P.; Claveria Guiu, I.; Choque, E.; Oliveira Souto, I.; Serre Delcor, N.; Blasco-Hernández, T. A Community-Based Intervention for the Detection of Chagas Disease in Barcelona, Spain. J. Community Health 2019, 44, 704-711. [CrossRef]

18. Meymandi, S.K.; Hernandez, S.; Forsyth, C.J. A Community-Based Screening Program for Chagas Disease in the USA. Trends Parasitol. 2017, 33, 828-831. [CrossRef]

19. Monge-Maillo, B.; Navarro, M.; Rodríguez, E.; Ramos Rincón, J.M.; Chamorro Tojeiro, S.; Jiménez Sánchez, S.; Casas del Corral, M.J.; López-Vélez, R. Community screening campaign for Strongyloides stercoralis among Latin American immigrants in Spain. Clin. Microbiol. Infect. 2018, 24, 1220-1221. [CrossRef]

20. Instituto Nacional de Estadística de España. Población extranjera por Nacionalidad, provincias, Sexo y Año. 2019. Available online: https://www.ine.es/jaxi/Datos.htm?path=/t20/e245/p08/\&file=03005.px\#!tabs-tabla (accessed on 6 May 2020).

21. Buonfrate, D.; Perandin, F.; Formenti, F.; Bisoffi, Z. A retrospective study comparing agar plate culture, indirect immunofluorescence and real-time PCR for the diagnosis of Strongyloides stercoralis infection. Parasitology 2017, 144, 812-816. [CrossRef]

22. Requena-Méndez, A.; Chiodini, P.; Bisoffi, Z.; Buonfrate, D.; Gotuzzo, E.; Muñoz, J. The laboratory diagnosis and follow up of strongyloidiasis: A systematic review. PLoS Negl. Trop. Dis. 2013, 7, e2002. [CrossRef]

23. Saugar, J.M.; Merino, F.J.; Martín-Rabadán, P.; Fernández-Soto, P.; Ortega, S.; Gárate, T.; Rodrígez, E. Application of real-time PCR for the detection of Strongyloides spp. in clinical samples in a reference center in Spain. Acta Trop. 2015, 142, 20-25. [CrossRef]

24. Buonfrate, D.; Salas-Coronas, J.; Muñoz, J.; Maruri, B.T.; Rodari, P.; Castelli, F.; Zammarchi, L.; Bianchi, L.; Gobbi, F.; Cabezas-Fernández, T.; et al. Multiple-dose versus single-dose ivermectin for Strongyloides stercoralis infection (Strong Treat 1 to 4): A multicentre, open-label, phase 3, randomised controlled superiority trial. Lancet Infect. Dis. 2019, 19, 1181-1190. [CrossRef]

25. Buonfrate, D.; Sequi, M.; Mejia, R.; Cimino, R.O.; Krolewiecki, A.J.; Albonico, M.; Degani, M.; Tais, S.; Angheben, A.; Requena-Mendez, A.; et al. Accuracy of Five Serologic Tests for the Follow up of Strongyloides stercoralis Infection. PLoS Negl. Trop. Dis. 2015, 9. [CrossRef]

26. Salvador, F.; Treviño, B.; Chamorro-Tojeiro, S.; Sánchez-Montalvá, A.; Herrero-Martínez, J.M.; Rodríguez-Guardado, A.; Serre-Delcor, N.; Torrús, D.; Goikoetxea, J.; Zubero, Z.; et al. Imported strongyloidiasis: Data from 1245 cases registered in the +REDIVI Spanish collaborative network (2009-2017). PLoS Negl. Trop. Dis. 2019, 13. [CrossRef] [PubMed]

27. Navarro, M.; Monge-Maíllo, B.; Flores-Chavez, M.D.; López-Vélez, R. Hunting hidden parasites: Trypanosoma cruzi. Lancet 2017, 390, 724-726. [CrossRef]

28. Abanyie, F.A.; Valice, E.; Delli Carpini, K.W.; Gray, E.B.; McAuliffe, I.; Chin-Hong, P.V.; Handali, S.; Montgomery, S.P.; Huprikar, S. Organ donor screening practices for Strongyloides stercoralis infection among US organ procurement organizations. Transpl. Infect. Dis. 2018, 20. [CrossRef] [PubMed]

29. Casado, L.; Rodriguez-Guardado, A.; Boga, J.A.; Fernández-Suarez, J.; Martínez-Camblor, P.; Rodríguez-Perez, M.; García-Pérez, A.; Vazquez, F.; Gascon, J. Use of serology in a systematic screening programme for strongyloidiasis in an immigrant population. Int. J. Infect. Dis. 2019, 88, 60-64. [CrossRef] [PubMed]

30. Salvador, F.; Treviño, B.; Bosch-Nicolau, P.; Serre-Delcor, N.; Sánchez-Montalvá, A.; Oliveira, I.; Sulleiro, E.; Aznar, M.L.; Pou, D.; Sao-Avilés, A.; et al. Strongyloidiasis screening in migrants living in Spain: Systematic review and meta-analysis. Trop. Med. Int. Health 2020, 25, 281-290. [CrossRef] [PubMed]

31. Van De, N.; Minh, P.N.; Van Duyet, L.; Mas-Coma, S. Strongyloidiasis in northern Vietnam: Epidemiology, clinical characteristics and molecular diagnosis of the causal agent. Parasit. Vectors 2019, 12, 515. [CrossRef] [PubMed] 
32. Dopico, E.; Rando-Matos, Y.; Solsona, L.; Almeda, J.; Santos, F.L.N.; Vinuesa, T. Infection by Strongyloides stercoralis in immigrants with Chagas disease: Evaluation of eosinophilia as screening method in primary care. Trop. Med. Int. Health 2019. [CrossRef] [PubMed]

33. Salvador, F.; Sulleiro, E.; Piron, M.; Sánchez-Montalvá, A.; Sauleda, S.; Molina-Morant, D.; Mourez, Z.; Molina, I. Strongyloides stercoralis infection increases the likelihood to detect Trypanosoma cruzi DNA in peripheral blood in Chagas disease patients. Trop. Med. Int. Health 2017, 22, 1436-1441. [CrossRef] [PubMed]

34. Salvador, F.; Sulleiro, E.; Sánchez-Montalvá, A.; Martínez-Gallo, M.; Carrillo, E.; Molina, I. Impact of Helminth Infection on the Clinical and Microbiological Presentation of Chagas Diseases in Chronically Infected Patients. PLoS Negl. Trop. Dis. 2016, 10. [CrossRef] [PubMed]

35. Echazú, A.; Juarez, M.; Vargas, P.A.; Cajal, S.P.; Cimino, R.O.; Heredia, V.; Caropresi, S.; Paredes, G.; Arias, L.M.; Abril, M.; et al. Albendazole and ivermectin for the control of soil-transmitted helminths in an area with high prevalence of Strongyloides stercoralis and hookworm in northwestern Argentina: A community-based pragmatic study. PLoS Negl. Trop. Dis. 2017, 11. [CrossRef] [PubMed]

36. Bisoffi, Z.; Buonfrate, D.; Sequi, M.; Mejia, R.; Cimino, R.O.; Krolewiecki, A.J.; Albonico, M.; Gobbo, M.; Bonafini, S.; Angheben, A.; et al. Diagnostic Accuracy of Five Serologic Tests for Strongyloides stercoralis Infection. PLoS Negl. Trop. Dis. 2014, 8, 38. [CrossRef]

37. Navarro, M.; Navaza, B.; Guionnet, A.; López-Vélez, R. A multidisciplinary approach to engage VFR migrants in Madrid, Spain. Travel. Med. Infect. Dis. 2012, 10, 152-156. [CrossRef]

38. Roger, D.; González-Escalada, A.; Navarro, M. Evaluación del conocimiento sobre Enfermedades Tropicales Desatendidas en estudiantes de sexto curso del grado en Medicina de la Comunidad Autónoma de Madrid; IV Congreso de Estudiantes de Medicina de la Universidad Rey Juan Carlos: Alcorcón, Madrid, Spain, 2017. Available online: https://eciencia.urjc.es/bitstream/handle/10115/13140/ISSN-2444-5479\%28IV\%29.pdf?sequence=16\& isAllowed $=y$ (accessed on 14 June 2020).

39. Salvador, F.; Sulleiro, E.; Sánchez-Montalvá, A.; Saugar, J.M.; Rodríguez, E.; Pahissa, A.; Molina, I. Usefulness of Strongyloides stercoralis serology in the management of patients with eosinophilia. Am. J. Trop. Med. Hyg. 2014, 90, 830-834. [CrossRef]

40. Buonfrate, D.; Requena-Mendez, A.; Angheben, A.; Cinquini, M.; Cruciani, M.; Fittipaldo, A.; Giorli, G.; Gobbi, F.; Piubelli, C.; Bisoffi, Z. Accuracy of molecular biology techniques for the diagnosis of Strongyloides stercoralis infection-A systematic review and meta-analysis. PLoS Negl. Trop. Dis. 2018, 12. [CrossRef]

41. Repetto, E.C.; Zachariah, R.; Kumar, A.; Angheben, A.; Gobbi, F.; Anselmi, M.; Al Rousan, A.; Torrico, C.; Ruiz, R.; Ledezma, G.; et al. Neglect of a Neglected Disease in Italy: The Challenge of Access-to-Care for Chagas Disease in Bergamo Area. PLoS Negl. Trop. Dis. 2015, 9. [CrossRef]

42. Fundación, M.S.; Madrid, S.; Salud, E.C. Evaluación de la Eficiencia de las Campañas de Cribado Comunitario de la Enfermedad de Chagas en Madrid; Informe de Evaluación de las Campañas 2014-2017: Madrid, España, 2018; Available online: https://www.saludentreculturas.es/wp-content/uploads/2019/05/Cascada-diagnostico-atratamiento-EChagas-Final.pdf (accessed on 14 June 2020).

43. Wikman-Jorgensen, P.; Llenas-García, J.; Shedrawy, J.; Gascon, J.; Muñoz, J.; Bisoffi, Z.R.-M.A. Cost-effectiveness of different strategies for Strongyloides stercoralis screening and treatment among migrants from endemic countries to the European Union. BMJ Glob. Health 2020, 5, e002321. [CrossRef]

44. Forsyth, C.; Meymandi, S.; Moss, I.; Cone, J.; Cohen, R.; Batista, C. Proposed multidimensional framework for understanding Chagas disease healthcare barriers in the United States. PLoS Negl. Trop. Dis. 2019. [CrossRef]

45. Navarro, M.; Navaza, B.; Guionnet, A.; López-Vélez, R. Chagas Disease in Spain: Need for Further Public Health Measures. PLoS Negl. Trop. Dis. 2012, 6. [CrossRef] [PubMed]

46. Agbata, E.N.; Morton, R.L.; Bisoffi, Z.; Bottieau, E.; Greenaway, C.; Biggs, B.A.; Montero, N.; Tran, A.; Rowutham, N.; Arévalo-Rodríguez, I.; et al. Effectiveness of screening and treatment approaches for schistosomiasis and strongyloidiasis in newly-arrived migrants from endemic countries in the EU/EEA: A systematic review. Int. J. Environ. Res. Public Health 2019, 16, 11. [CrossRef] [PubMed] 
47. Van Der Werf, J.; Derrough, T.; Duffell, E.; Pharris, A.; Suk, J.; De, H.; Mardh, O.; Velasco Muñoz, C.; Causevic, S.; Thoft Nielsen, R.; et al. Public Health Guidance on Screening and Vaccination for Infectious Diseases in Newly Arrived Migrants within the EU/EEA, 1st ed.; European Centre for Disease Prevention and Control: Stockholm, Sweden, 2018; pp. 1-77. [CrossRef]

48. Clemente, W.T.; Pierrotti, L.C.; Abdala, E.; Morris, M.I.; Azevedo, L.S.; López-Vélez, R.; Cuenc-Estrella, M.; Torre-Cisneros, j.; Petersen, E.; A Camargo, L.F.; et al. Recommendations for Management of Endemic Diseases and Travel Medicine in Solid-Organ Transplant Recipients and Donors: Latin America. Transplantation 2018, 102, 193-208. [CrossRef] [PubMed]

(C) 2020 by the authors. Licensee MDPI, Basel, Switzerland. This article is an open access article distributed under the terms and conditions of the Creative Commons Attribution (CC BY) license (http://creativecommons.org/licenses/by/4.0/). 